\title{
ARTIGOS
}

\section{O PENSAMENTO SEM ESTACA ZERO (A MENTALIDADE EXTERNALISTA E AS RAZÕES NOSSAS DE CADA DIA $)^{I}$}

Hilan Bensusan*

RESUMO O reconhecimento de uma autoridade (de fatos, de observações compartilhadas, de princípios comumente aceitos etc.) por parte de quem se convence é o que buscamos quando nos engajamos em uma prática de oferecer razões para um pensamento ou uma ação. Parece que o ato do reconhecimento é um elemento constitutivo do estado em que temos (ou aceitamos) razões. Por outro lado, muitas vezes estamos inclinados a dizer que temos ou não temos razão; como se, caso a tenhamos, o reconhecimento da autoridade da nossa razão seja compulsório. Por vezes, quando nos movemos no espaço das razões, temos a impressão de que elas já estão lá, de que elas são independentes do nosso melhor julgamento, e o melhor que temos a fazer é aprender a ficar sensiveis a elas. Neste texto examino o realismo quanto a razões como uma formulação do externalismo e considero as conexões entre externalismo em semântica e em epistemologia. Argumento que um realismo quanto a razões pode fazer uso de uma estratégia davidsoniana para conciliar a idéia de que razões estão no mundo com a concepção destas últimas segundo a qual o reconhecimento lhes é constitutivo.

* Professor Adjunto do Departamento de Filosofia da Universidade de Brasília. Artigo recebido em outubro de 2004 e aprovado em novembro de 2004. (hilanb@unb.br)

1 Este texto foi sensivelmente melhorado a partir das observações e discussões com as pessoas que participaram do Colóquio Externalismo e Internalismo, na primavera de 2003, em Belo Horizonte. Agradeço a Ernesto Perini e à organização do evento pela oportunidade de apresentar uma versão esboçada das preocupações deste texto no Colóquio. Ali, o texto se chamava "Para começarmos da estaca zero, deve haver uma estaca zero". Também gostaria de agradecer a André Porto e aos organizadores do Pio da Coruja, no Departamento de Filosofia da UFG, pelo convite para discutir uma outra versão preliminar deste trabalho, entitulada "Um mundo de fatos e as razões no mundo".

KRITERION, Belo Horizonte, nº 110, Dez/2004, p. 209-223 
Palavras-chave Razões, externalismo, Annerkenung, Davidson

ABSTRACT When we offer reasons for a belief or an action we prompt the audience to recognize authorities (of facts, of shared observations, of commonly held principles etc.). This recognition seems to be constitutive of the very state we find ourselves in when we have or accept reasons. On the other hand, often we are inclined to say that either we have or we don't have reasons for something; we sound as if in case we have reasons, their acceptance is compulsory. Sometimes, when we move in the space of reasons we have the impression that reasons are already there, that they are independent from our best judgment and we should rather learn to be sensitive to their claim. In this paper I consider realism about reasons as a way of stating externalism and I then examine connections between externalism in semantics and in epistemology. I argue that a realism about reasons could make use of a Davidsonian strategy to put together the idea that reasons are in the world with the conception according to which recognition is part of what constitutes a reason.

Key-words Reasons, externalism, Annerkenung, Davidson

An interpreter that starts from scratch cannot independently discover what an agent's beliefs are about, and then ask whether they are true.

Davidson (1991, p. 195)

1. Somos nós que pedimos razões, nós que oferecemos razões. Somos nós que nos contentamos com as razões que nos são oferecidas ou que requisitamos mais razões para o nosso contentamento. Justificar parece envolver o esforço para conseguir o assentimento de alguém. Ainda assim, algumas vezes é plausível dizer que, ou nós temos razão, ou nós não temos razão (com respeito a alguma coisa suficientemente especificável). Pode ser que não saibamos quem tem razão, pode ser que nunca venhamos a saber quem tem razão, mas ainda assim alguém haverá de ter razão. Por um lado, parece que nos movemos no espaço das razões motivando pessoas a dar certos passos por meio do reconhecimento de alguma autoridade que as faria se moverem para alguma direção. O reconhecimento de uma autoridade (de fatos, de observações compartilhadas, de princípios comumente aceitos etc.) que reconhecemos por parte de quem queremos convencer é o que parece que estamos buscando quando nos engajamos em uma prática de oferecer razões para uma crença ou uma ação. Parece assim que o ato do reconhecimento é um elemento constitutivo do estado em que temos (ou aceitamos) razões. Por outro lado, muitas vezes 
estamos inclinados a dizer que temos ou não temos razão; como se, caso a tenhamos, o reconhecimento da autoridade da nossa razão seja compulsório. Por vezes, quando nos movemos no espaço das razões, temos a impressão de que elas já estão lá, de que elas são independentes do nosso melhor julgamento, e o melhor que temos a fazer é aprender a ficar sensíveis a elas - queremos saber distinguir as boas razões das que apenas parecem ser boas. Nosso conflito então parece ser que, de um lado, pensamos que as razões dependem de quem as reconhece e, de outro, que elas por vezes parecem estar no mundo. Gostaria de começar dizendo algumas coisas sobre esse conflito e, em seguida, examinar como podemos tentar dissolvê-lo.

2. A conexão entre razões e Anerkennung parece surgir de uma idéia de conhecimento segundo a qual eu não posso conhecer nada à minha revelia. $\mathrm{O}$ conhecimento, diz Wittgenstein em Da Certeza, § 378, está baseado no reconhecimento. Tem-se a impressão de que eu tenho que dar o meu assentimento para que eu conheça alguma coisa. Podemos talvez modificar a idéia de modo a que seja suficiente que alguma pessoa faça o reconhecimento para que possa atribuir a mim o conhecimento, como quer insistir Brandom (1994), por exemplo. Mas parece que, se não há reconhecimento, estamos em um domínio de leis naturais apenas, um domínio de heteronomia. O reconhecimento é um ato responsável que, de alguma maneira, instaura a justificação: podemos argumentar porque podemos pensar do modo como pensamos, mas podemos também pensar de outros modos -- a autoridade das razões requer Anerkennung para a sua efetividade; fora do reconhecimento, sobra apenas a influência das causas. É o requisito do reconhecimento que distingue o que nós fazemos (e pensamos) por uma compulsão dita natural - determinada por motivos independentes de qualquer exercício de autonomia — do que fazemos quando nos movemos no espaço das razões, quando obedecemos de algum modo a algum ideal constitutivo da racionalidade.

Uma maneira de dar substância às intuições associadas à Anerkennung, apenas uma das diferentes maneiras de dar substância a essas intuições, é admitir que as razões são apenas nossos instrumentos para alcançarmos o mundo - que razões estão apenas na cabeça de quem se convence. Podemos nos convencer de que o mundo não é feito de razões, e somos nós que projetamos razões nele. Alguns projetos epistemológicos tradicionais parecem assumir que razões são projeções em um mundo desencantado. Razões são aquilo que me convence, ou aquilo que deve me convencer - por exemplo, aquilo que convenceria uma mentalidade cética. Ou seja, uma razão é aquilo que comanda uma Anerkennung. Meu ponto de partida é o mundo com o qual eu tenho a 
impressão de interagir, mas sobre o qual não conheço nada. E o mundo com o qual eu interajo aparece como uma autoridade, e eu já o aceito como fonte de autoridade, ainda que eu não saiba nada dele. Surge alguma coisa que me parece compulsório que eu aceite. Razões são o que nos dá direito a acreditar no que acreditamos. O pássaro é vermelho, ainda que seja verdade, não é ainda uma razão para que eu acredite que o pássaro é vermelho. Minha razão é algo que comanda o meu assentimento - e também ou talvez apenas o assentimento de outras pessoas - de que o pássaro é vermelho. Razões são vistas como redes que nós lançamos em direção ao mundo. De acordo com essa forma de pensar, razões são nossa maneira de alcançar as verdades; elas são o caminho, a escada que precisamos subir porque nós estamos onde estamos - outras criaturas em busca de verdade poderiam usar outros caminhos e chegariam às mesmas verdades, mas viriam do outro lado. Em certo sentido, não importa tanto o caminho que façamos, importa apenas que ele possa nos levar aonde queremos ir. Quando alcançamos a conclusão cética de que não há razão suficiente para que tenhamos direito a qualquer crença, dizemos que não há caminho legítimo para nos levar às verdades às quais queremos chegar: não concluímos nada sobre o mundo, apenas que não podemos chegar a ele.

Um tema que podemos encontrar, recorrentemente, do esforço de Hegel na Fenomenologia do Espírito (1807) é a crítica ao que subjaz esta maneira de pensar as razões como instrumentos. Hegel diagnostica que essa maneira de pensar repousa na idéia de que os objetos que queremos conhecer são independentes do instrumento (do caminho, das redes) que utilizamos para a eles chegar. Ele contra-argumenta que se descartarmos as razões que nos levaram a conhecer os objetos, abandonaremos os objetos mesmos; sem as razões que nos fazem conhecer, não sobra objeto algum. Ou seja, se pudermos retirar do objeto conhecido todo o esforço de pensamento que usamos para conhecê-lo, por exemplo, os conceitos com os quais pensamos, não nos sobra objeto conhecido. A argumentação assim pode soar a alguns ouvidos inteiramente verificacionista: há aqui uma rejeição da possibilidade de que os objetos possam transcender nossa capacidade de conhecê-los. Podemos talvez evitar parte do incômodo que essa impressão pode gerar se pensarmos que as razões podem, elas mesmas, transcender a nossa capacidade de conhecê-las. Podemos, em outras palavras, postular que as razões estão no mundo, e não separadas dele em um domínio mental restrito como em um Teatro Cartesiano. Um realismo acerca das razões, concebido assim, parece ser fortemente encorajado por uma rejeição de uma imagem cartesiana dos nossos conteúdos mentais e, em geral, da concepção em que a mente pode ser vista como uma variável independente do mundo. Ou seja, parece que um externalismo quanto a conteúdos pode ser 
posto a serviço da motivação de um realismo quanto a razões. ${ }^{2} \mathrm{O}$ realismo quanto a razões - e o gênero do qual penso que ele é uma espécie, o externalismo epistemológico - é o um pólo do conflito do qual a tradição da Anerkennung é o outro pólo. De um lado, a idéia de que razões não são nem projeções nossas no mundo e nem apenas parte de nossa vida mental independentemente do contato que nossos conceitos e normas fazem com o ambiente que nos circunda. De outro, a idéia de que razões só possuem autoridade - e, portanto, podem atuar sobre nossos pensamentos e ações e ser caracterizadas como razões - por meio de algum ato de Anerkennung.

A maneira de pensar que Hegel critica, segundo a qual razões são projeções nossas, nossa segunda criação, sustenta também uma perspectiva sobre o conhecimento que entende as razões para nossas crenças como sendo separadas tanto do conteúdo delas quanto do seu valor de verdade. Parece de novo que o mundo está separado de nós por um abismo, e conhecê-lo é atravessar o golfo com razões. Essa é a imagem que a mentalidade externalista se empenha em exorcizar. Uma das avenidas mais transitadas em direção ao externalismo em epistemologia é a idéia de que este golfo deve ser atravessado não por alguma embarcação que nos pareça firme e segura, mas por um navio que seja firme e seguro, quer saibamos disso ou não. Os exemplos como os de Gettier podem ser entendidos como apontando para os vínculos que devem existir entre aquilo em que acreditamos e as razões para que acreditemos naquilo para haver conhecimento: sem esses vínculos, não podemos pensar que temos razões para acreditar no que acreditamos; podemos até acreditar em verdades mas não teremos razões para acreditar nelas. Podemos compreender os exemplos como nos encorajando a entender o conhecimento requerendo, de certo modo, mais do que uma relação contingente - uma coincidência - entre nossas justificações e a verdade. O externalismo epistemológico promove um passo em direção a abandonar a dicotomia entre nossas razões e o mundo no qual nós as projetamos para tentar conhecer alguma coisa: as razões, quer saibamos ou não, estão no mundo. Trata-se de uma mentalidade que procura encará-las a partir de uma perspectiva que independe de quem elas convencem — de uma perspectiva de terceira pessoa. Nós podemos conhecer sem ser capazes de mostrar que conhecemos. Uma analogia seria insistir que um teorema não precisa de uma prova de que ele esteja provado para estar provado: basta que ele esteja provado. Razões nos conectam aos objetos que conhecemos;

2 As razões podem estar no mundo de um modo satisfatório para uma maneira de pensar naturalista se entendermos o externalismo de um modo confiabilista e o confiabilismo como Goldman (1986; 1998) o recomenda. Nesse caso, as razões seriam leis acerca da confiabilidade de certos processos. 
não precisamos saber que elas são boas razões para que os conheçamos — basta que elas sejam.

3. Neste ponto, posso já esboçar em linhas gerais que caminho recomendo que tracemos para conciliar uma mentalidade externalista com a manutenção de elementos da tradição da Anerkennung.

Um realismo quanto a razões toma uma visão de terceira pessoa acerca delas. Não vemos o mundo a partir de nossas razões, mas pensamos que podemos ver as razões e o mundo de uma perspectiva de terceira pessoa. Uma visão de terceira pessoa nos põe a ver razões desde fora, isto é, sem estarmos a reconhecer a sua autoridade para que elas sejam efetivas. O conflito que quero explorar aparece aqui na forma do debate sobre a autoridade de primeira pessoa. Como Davidson uma vez apresentou o impasse (1987), o externalismo pode até nos convencer de que temos razões para acreditar na maioria das nossas crenças e, portanto, exorcizar um ceticismo global, mas o preço que ele cobra é terminarmos sem saber o que pensamos. A concepção de razões que emerge da tradição da Anerkennung requer que crivemos com o reconhecimento da autoridade de uma razão para que ela possa efetivamente influenciar o nosso pensamento e a nossa ação. Um realismo quanto a razões, conjugado ou motivado por um externalismo de conteúdos, pode parecer tornar possível que eu não saiba o que eu penso e nem por que eu penso o que eu penso.

Externalistas como Putnam e Burge sentiram-se encorajados em rejeitar a idéia de que temos uma autoridade especial sobre o que nós pensamos, e, de fato, acomodar essa autoridade, de um ponto de vista externalista, parece um problema aberto. Acredito que podemos, no entanto, argumentar que sabemos, em alguma medida, o que pensamos, pois pensar (também sobre o que pensamos) requer que saibamos alguma coisa. Davidson insiste que a presunção de verdade em favor de nossas crenças, que é um requisito para que sejamos interpretáveis e que nossas crenças tenham conteúdo, se aplica também ao que nós acreditamos que acreditamos. Não podemos estar errados acerca de tudo o que pensamos que acreditamos; se assim fosse, não pensaríamos coisa alguma. Se é assim, talvez tenhamos um esboço de uma maneira de conciliar uma mentalidade externalista com a tradição da Anerkennung: para termos conteúdos em nossa vida mental, precisamos reconhecer algumas autoridades; sem conteúdo, não podemos nem estar sensíveis a razões e nem sequer podemos ter razão no que quer que nós pensemos. Trata-se ainda de um esboço porque ainda temos que saber como podemos pensar nas razões de um modo que seja, ao mesmo tempo, compatível com a idéia de que elas existem para 
além do acesso que temos a elas e capaz de satisfazer o requisito de que razões requerem Anerkennung para serem efetivas.

4. Antes de dar mais substância a este esboço, vou tentar explorar um pouco mais o pólo externalista, em especial como o externalismo quanto a conteúdos se relaciona com o externalismo epistemológico.

Para que razões estejam no mundo, é preciso que algumas outras coisas que se entrelaçam com razões não sejam itens inteiramente indiferentes a como o mundo é (indiferentes às razões que há no mundo). Freqüentemente, quando aderimos à imagem de que razões são projeções nossas no mundo, pensamos que conteúdos dos estados mentais só podem depender do que sabemos sobre o mundo; jamais do mundo, independentemente do que sabemos. Conteúdos de estados mentais são matéria-prima para razões e, se elas são nossas projeções, não podemos identificar seus conteúdos com base em qualquer outra coisa a não ser outros conteúdos dos nossos estados mentais. Se não procedermos assim, estaremos passando ao largo da distinção entre nosso pensamento e o mundo sobre o qual tentamos pensar. Estaremos também incorrendo no risco de uma petição de princípio: fazer uso do que sabemos sobre o mundo para, por exemplo, atribuir conteúdo a crenças; pensamos o que pensamos com base nas nossas razões, se razões são nossas, também o conteúdo do que pensamos não pode ser especificado com o auxílio do mundo. Pensamentos, enquanto pensamentos, são neutros acerca de como o mundo é.

Se somos realistas com respeito às razões, por outro lado, temos que admitir que acreditamos, tememos e pensamos em partes do mundo. Nossa vida mental deve então ser constituída por elementos do mundo. Podemos ter itens de nossa vida mental que não conhecemos — podemos não saber o que pensamos. Por outro lado, para que tenhamos pensamento com conteúdo, temos que saber certas coisas do mundo - por exemplo, as razões que conduzem nosso pensamento em uma direção ou em outra — ; ainda que não saibamos que sabemos. Je pense, donc je sais. ${ }^{3}$ A especificação dos conteúdos dos nossos estados mentais não pode ser feita sem apelo ao ambiente à nossa volta. McDowell (1982; 1994) tem insistido que, quando conhecemos ou percebemos, nossos conteúdos não têm nada em comum com quando temos crenças falsas ou alucinamos. Diante de um oásis e diante de uma miragem nossos estados são diferentes, apesar das aparências, e não há um máximo conteúdo comum entre os dois casos. Se eu não sei se conheço ou não, mas posso conhecer, meu

3 Versão do Cogito que Thomas Nagel (2000) atribuiu a Davidson. 
estado envolve um objeto conhecido, no caso do oásis, e algo completamente diferente, no caso da miragem. Os estados mentais — os veículos das razões que não são meras projeções nossas no mundo -- não poderiam ser mais diferentes. A semelhança da aparência entre esses dois estados mentais, do ponto de vista de quem os têm, nos conta apenas sobre a dificuldade de discernir entre um estado e outro, e não sobre sua possível similaridade, e menos ainda sobre a necessidade de postular um elemento (de conteúdo) comum entre os dois estados. O externalismo, portanto, parte da suposição de uma relação entre mente e mundo que contrasta, logo de início, com aquela em que nós temos a obrigação de poder separar uma coisa da outra.

Greg McCulloch (2003) apresenta o argumento de Putnam em favor do externalismo semântico de um modo que faz com que o externalismo pareça conseqüência de uma maneira de pensar minimamente fregeana (em conjunção com algumas outras suposições prima facie plausíveis como a rejeição de uma distinção entre conteúdos amplos e conteúdos estritos). Se Sinne determinam Bedeutungen, termos com diferentes Bedeutungen não podem ter Sinne diferentes. Basta isso para que tigres e schmigres, água e tágua ${ }^{4}$ tenham sempre Sinne diferentes. McCulloch entende assim o externalismo semântico como sendo compulsório para uma postura fregeana. Uma manobra parecida pode ser tentada a partir da recusa da idéia de idéia e de argumentos contra a existência de uma linguagem privada. O conteúdo de nossas crenças só pode ser identificado a partir de um esquema de correção que não pode estar expressa em "mentalês". Nossa vida mental não é alheia ao mundo — não é uma variável independente - , e isso pode ser insinuado pelo esforço de Wittgenstein no argumento contra a existência de uma linguagem privada em que, como uma vez caracterizou Cavell (1969, p. 91), se trata de despsicologizar nossa psicologia. Por um caminho fregeano ou wittgensteiniano podemos sentir uma repulsão pelos pressupostos que contrastam com o externalismo semântico. O conteúdo dos nossos estados mentais não parece ser insensívl a como é o resto do mundo; um confinamento do mundo fora da mente exigiria que ela pudesse pensar e ter, portanto, normatividade, independentemente de qualquer outro elemento do mundo.

Se conseguimos nos persuadir de que o conteúdo de nossos estados mentais depende do mundo externo à mente, fica parecendo razoável que também nossa atitude diante desses conteúdos responda ao mundo. Segue que se crenças

4 "Tágua" e "Schmigre" são entendidos na discussão sobre externalismo como itens indistinguíveis na aparência de água e tigre respectivamente. A estrutura interna de água e tágua, por exemplo, é que seria diferente, imaginamos tágua como tendo uma estrutura molecular $\mathrm{XYZ}$, diferente de $\mathrm{H}_{2} \mathrm{O}$. 
são estados mentais que dependem do mundo, também conhecimentos são estados mentais que dependem dele. Não temos dois fatores justapostos quando temos conhecimento; um fator mental e um fator factual - nem mesmo três, se considerarmos o fator racional. Externalistas, como McGinn (1984) e Timothy Williamson, recomendam que entendamos o conhecimento como um conceito mais primitivo que o de crença justificada. A imagem que emerge é que o conhecimento é uma relação que temos com o mundo, que faz parte do mundo e a partir da qual começamos nosso processo de encontrar razões e procurar evidências para as crenças. Timothy Williamson (2000) entende que a evidência a nosso dispor é o conjunto do nosso conhecimento. Cada evidência requer outra evidência; o fim do regresso é o que conhecemos - quando o que conhecemos está disponível para podermos usar em nosso esforço de oferecer razões. A partir do externalismo semântico, com os conteúdos dos estados mentais determinados pelo mundo, nossas razões deixam de ser transparentes a nós: nosso poder de discriminar razões não pode ser mais o último juiz das razões. Nossas razões para agir e pensar deixam de ser meras projeções nossas desde fora do mundo.

5. Postular que as razões estão no mundo é abrir mão de uma certa perspectiva de primeira pessoa que enxerga nossas razões e as crenças que elas produzem como atrizes em um Teatro Cartesiano, sempre de portas fechadas. A mentalidade cartesiana que instaura o Teatro, como uma vez diagnosticou Rorty (1970), parte de alguma motivação para decidir que nossos relatos de primeira pessoa são tais que nós temos a autoridade última acerca deles como não temos acerca de nada mais. Instaurada essa autoridade especial, podemos conhecer nossa vida mental sem saber nada sobre o mundo e, assim como o mundo é irrelevante para nossa vida mental, podemos conhecer tudo o que se passa em nossas mentes pondo o mundo entre parêntesis. De dentro do Teatro, falamos sobre o mundo em primeira pessoa e sempre através do filtro de nossas crenças; o filtro que, concedida essa autoridade especial, recebe a marca da incorrigibilidade. Se, por intermédio desse filtro, de alguma maneira conseguimos representar o mundo lá fora (se de algum modo conseguimos ver pela janela), conseguimos dizer que o conhecemos. Como nossa vida mental é indiferente ao mundo, de acordo com essa perspectiva que o externalismo procura evitar, aparecem de toda parte dúvidas céticas. O Teatro pode estar no meio de um sonho, pode ser a alucinação de um cérebro espetado de eletrodos. Mas o Teatro segue apenas da conclusão que Descartes e muitos outros se sentem encorajados a tirar a partir da premissa je pense --Davidson, como vimos, talvez concluísse donc je sais, de acordo com Nagel, ou provavelmente, 
como ele disse uma vez, estaria encorajado a concluir donc tu es. É difícil dissolver as dúvidas céticas, no entanto, uma vez encontrada uma atmosfera na qual elas respiram livres do ônus de ter que provar sua legitimidade - e a atmosfera do Teatro é a melhor que elas podem encontrar - , pode parecer que elas são inevitáveis toda vez que começamos a pensar no contato entre mente e mundo.

Um exorcismo externalista das dúvidas céticas começa por criticar a suposição de que o mundo não faz diferença na nossa vida mental: é mais razoável imaginar que muitas vezes não percebemos o mundo atuando sobre nossos estados mentais do que postular uma completa insensibilidade da mente ao mundo toda vez que podemos fazer com que ele pareça irrelevante. A dúvida cética parte da suposição de que podemos entender as crenças -- e dar razões para as ações - em um estado de indiferença acerca do mundo. A diluição do Teatro Cartesiano e a postulação de razões para além da nossa capacidade de distingui-las podem não ser suficientes para afugentar os temores céticos. Pode parecer que o externalismo, ao tornar o conhecimento inteligível, sem apelar para janelas no Teatro, é capaz de separar a questão da inteligibilidade do contato com o mundo da questão da pertinência da dúvida global — de despachar, portanto, o ceticismo como a questão fundamental sobre o nosso acesso ao mundo. Mas isso pode parecer insuficiente se pretendemos dar algum tipo de solução para o problema cético.

Michael Williams pensa que uma solução para a dúvida cética envolve diagnosticar a sua origem. Para ele, isso significa entender como nos colocamos na situação em que ou aceitamos logo o ceticismo, ou damos "voltinhas" antes de aceitá-lo - o aceitamos sob disfarce. Essa situação é o que ele apelida de dilema do epistemólogo e, no caso do externalismo, o dilema aparece assim:

Os obstáculos céticos ao conhecimento simplesmente põem-se outra vez em segunda ordem. Se eles são obstáculos genuínos, mas não podem ser superados, não será uma resposta adequada ao ceticismo dizer que apesar de que nós podemos muito bem saber todo tipo de coisa, nós podemos não ter nenhum elemento para supor que nós de fato sabemos qualquer uma delas. Por outro lado, se os obstáculos não precisam ser superados, isso precisa ser mostrado antes que nós decidamos em favor de um entendimento externalista do conhecimento. (1996, p. 98, tradução minha).

O externalismo, com sua insistência de que não precisamos ser capazes de apresentar razões para estarmos em condição de saber alguma coisa, pode parecer apenas um adiamento do problema cético. $\mathrm{O}$ problema nos pega na esquina: e aí, como podemos alguma vez saber que sabemos alguma coisa? O conhecimento, é claro, pode se tornar inteligível em paz, sua inteligibilidade 
pode ser posta a salvo dos assaltos céticos; mas os assaltos continuam acontecendo - apenas talvez percam um pouco do seu drama, porque, em algum sentido, não estamos mais confinados no nosso mundo de aparências indiferentes ao mundo, podemos estar apenas (contingentemente) ignorantes. Barry Stroud observa que, para não se desviar do problema que a dúvida cética põe em questão, o externalismo deve pelo menos dizer que

[...] tem boas razões para crer [nas relações com o mundo que podem ocorrer de vez em quando], em um sentido de "boas razões" que não pode ser capturado completamente em uma abordagem externalista. (1989, p. 47, tradução minha).

De fato, a argumentação externalista tipicamente tenta nos persuadir de que nossas mentes não podem estar em completo isolamento do resto do mundo e, portanto, nossas relações com o mundo não podem deixar de existir. $\mathrm{O}$ externalismo deve pensar que há bons motivos para pensar assim e que nós devemos nos persuadir deles. Ter esses bons motivos, e não no sentido apenas de que eles estejam disponíveis em alguma parte, é um ponto de partida para uma maneira externalista de pensar. É um ponto de partida para diluir a incorrigibilidade do Teatro Cartesiano em um meio onde não há uma Distinção Real entre uma arena acerca da qual sabemos tudo - mente - e uma outra acerca da qual somos completamente ignorantes - mundo. De alguma forma, então, a plausibilidade do externalismo requer razões ao nosso dispor - como, de resto, sua implausibilidade. Ao fim, o externalismo parece não ser suficiente para estabelecer que temos um contato com o mundo, mesmo se aceitarmos uma maneira externalista de entender este contato - - a inteligibilidade do conhecimento não implica, pelo menos aos olhos céticos, que ele alguma vez aconteça. Aqui parece que encontramos uma situação em que o desacordo entre as mentalidades que nutrem o ceticismo e a maneira externalista de entender as razões e nosso contato com elas está distribuído em muitos âmbitos: o externalismo pode estar a oferecer um diagnóstico acerca do que sustenta a atitude cética, mas esse diagnóstico, por sua vez, parece repousar já em uma recusa do ponto de vista de primeira pessoa como sendo compulsório e em um realismo sobre razões. ${ }^{5}$ Podemos pensar que um procedimento externalista

5 Um realismo quanto a razões requer que tenhamos uma teoria sobre razões insuficientes ou sobre más razões. Esse ponto foi observado por Plínio Junqueira Smith, em discussão no Colóquio Externalismo e Internalismo. Penso, em primeiro lugar, que as más razões são identificadas como más razões apenas sobre o pano de fundo de razões que tomamos como sendo boas. Há uma presunção associada a cada razão de que elas sejam boas. Além disso, penso que as más razões não podem ser consideradas como estando no mundo. O realismo acerca de razões é um realismo acerca das boas razões. As más razões não têm, apesar das aparências, nada ontologicamente em comum com as boas razões. Valem aqui as observações de McDowell (1982) contra um máximo fator comum entre a percepção e a alucinação. 
pode ser aquele de forçar a personagem cética a comprometer-se com teses substantivas, a ter que defender a idéia de um Teatro em que a mente é soberana, alheia à comunidade, alheia ao resto do mundo.

6. Como conciliar externalismo e Anerkennung? Conforme insinuei anteriormente, acredito podermos modular o externalismo que permite que tenhamos uma agenda para dissolver o medo do ceticismo com elementos da tradição da Anerkennung. Penso que podemos insistir, com Davidson (1987), que conhecemos grande parte do que acreditamos: um engano sistemático ou global sobre o que pensamos nos tornaria ininteligíveis, sem conteúdo. Se temos conteúdos, temos algumas razões e pensamos no mundo com base nas razões que informam o conteúdo do nosso pensamento. Quando dizemos, por exemplo, que podemos não saber as razões que nos levam a acreditar em conclusões de procedimentos indutivos, temos que saber das razões que nos levam a nos perguntar, por exemplo, se o futuro espelha o passado - essa pergunta requer que no universo haja relógios, e essa razão temos que ter, ou seja, temos que reconhecer, para que possamos formular nossa questão acerca dos procedimentos indutivos. Dito de outra maneira, não podemos ter uma vida mental desprovida de razões, mesmo que razões não sejam apenas nossas projeções. Se razões estão no mundo -- e com isso queremos dizer que as razões que, de algum modo, são aquelas que devem comandar nossa Anerkennung estão no mundo - , elas estão também na nossa vida mental: nossa vida mental não acontece de fora do mundo, de fora das razões. Também podemos dizer, com o auxílio dos argumentos de Davidson, que temos de conhecer algumas das (boas) razões que estão no mundo; ou seja, não é possível que as razões que estejam no mundo sejam inteiramente distintas daquelas que participam da nossa vida mental. Se fosse assim, não poderíamos jamais reconhecer (ah, Anerkennung) as razões externas como razões. Do meu ponto de vista, eu só posso ser inteligível para alguém se parte de minhas razões for compartilhada; do ponto de vista de nossas razões comuns, as razões externas a nós só podem ser inteligíveis sobre um pano de fundo das nossas razões. É claro que alguém pode resistir a essas manobras davidsonianas insistindo que as razões, no mundo, podem ser completamente opacas a nós. Se for assim, perdemos tanto a possibilidade de conhecer o que pensamos, quanto a de exorcizar um desafio cético formulado assim: aquilo que nós pensamos que sabemos pode estar globalmente equivocado (ainda que o que saibamos esteja correto). Uma alternativa assim nos deixaria sem conhecimento de nossa mente e sem qualquer acesso ao mundo por meio do nosso esforço de pensamento. Uma alternativa como essa jogaria fora a Anerkennung junto com a água do banho do internalismo. 
Penso que um externalismo naturalista é um caminho possível para implementar esta última alternativa. Desse modo, entendemos as razões como sendo basicamente leis da natureza, e nosso conhecimento (ou reconhecimento) delas é desnecessário para que elas atuem sobre nós. Um naturalismo assim deixaria de lado qualquer tentativa de explicar como nossa vida mental se conecta com o mundo por meio de elementos acessíveis ao nosso pensamento; desistimos do acesso ao mundo por parte de nossos pensamentos ou de nossa mente e basta que estejamos, de fato, em uma relação adequada com o mundo para conhecê-lo. Trata-se de colocar a epistemologia em um paradigma de heteronomia, como diria Kant, ou de entender razões da maneira como entendemos os ingredientes do domínio das leis. Parece que, quanto à mente, um tal externalismo teria que abraçar alguma forma de eliminativismo. Nesse caso, tem-se um realismo quanto a razões com toda a sua força, e deixamos de lado o outro pólo do conflito aparente que me interessa.

Penso que essa alternativa naturalista não é recomendável, por deixar algumas formas de ceticismo intocadas, por tornar nossa vida mental e as razões inteiramente opacas e por dispensar as intuições que movem a tradição da Anerkennung. Minha alternativa é, antes, a de que algumas razões (que são objetos do mundo) devem estar presentes em nossa vida mental para que possamos reconhecer razões e para que tenhamos conteúdos em nossas crenças. A imagem que gostaria de sugerir para tornar mais explícita essa forma de externalismo que se concilia com a tradição da Anerkennung é a imagem de um espaço das razões que compõem o mundo: razões transcendem nossa capacidade de julgamento porque elas estão no mundo, mas estar no mundo não significa ainda ser inteligíveis com os recursos do domínio das leis. É apenas porque há práticas de oferecer e demandar por razões que algumas razões são melhores que outras - merecem comandar mais Anerkennung. Esse merecimento, no entanto, é completamente dependente das razões que nós já aceitamos, são elas que nos fazem reconhecer outras razões. As razões estão presentes quando há pensamento - trata-se talvez de uma doutrina aparentada com o platonismo naturalizado defendido por McDowell (1994). As razões estão na natureza mas elas dão conteúdo à nossa vida mental e, do ponto de vista de nossa vida mental, é que nós reconhecemos razões.

Razões requerem reconhecimento para poderem ser efetivas; elas apenas podem ser reconhecidas de dentro, isto é, a partir de quem possui razões e é sensível a elas. $O$ espaço das razões não pode portanto ser alienígena, indiferente ao nosso reconhecimento. Pode haver razões que não estão ainda pensadas ou consideradas por quem quer que seja, mas elas devem poder ser reconhecíveis à luz das razões que nós tomamos como boas razões —e a maioria das 
nossas razões são boas razões, razões existentes. Uma proposta externalista que seja também eliminativista é uma proposta que parece apenas deixar de lado a nossa vida mental — torna o conhecimento, as crenças, a justificação e qualquer variável da nossa relação com o mundo externos à nossa vida mental, de modo a entender a nossa impressão de pensamento como um epifenômeno. Se, por outro lado, o espaço das razões é acessível à nossa vida mental, embora não seja redutível a ele, e se o espaço das razões constitui nossa vida mental, embora não seja alheio ao resto do mundo, podemos de fato ter um modelo da nossa mente que esteja todo o tempo em contato com o mundo e que não funcione como um Teatro Cartesiano. Sustentar que os conteúdos da nossa mente estão no mundo não precisa ser o mesmo que sustentar que nossa vida mental, tal como nós a conhecemos, é irrelevante. Vemos o mundo, e as razões nele, a partir das razões que constituem nossa vida mental — nossa vida mental não está fora do mundo, mas é a parcela dele de onde parte nosso pensamento.

\section{Referências}

BRANDOM, R. Making it Explicit. Harvard/Mass.: Harvard University Press, 1994. CAVELL, S. Must we mean what we say? Nova York: Charles Scribner and Sons, 1969.

DAVIDSON, D. Knowing one's own mind. Proceedings and Addresses of the American Philosophical Association, p. 441-458, 1987.

Epistemology externalized. Dialectica, 45, 1991.

GOLDMAN, A. Epistemology and Cognition. Cambridge (MA): Harvard University Press, 1986.

. Epistemologia naturalista e confiabilismo. Cadernos de História e Filo-

sofia da Ciência. F. Évora e P. Abrantes (Ed.). v. 8, n. 2, p. 109-145, 1998. (CLE UNICAMP, Série 3).

HEGEL, G. F. Fenomenologia do Espírito. Vozes. (Primeira edição alemã: 1807).

McCULLOCH, G. The Life of the Mind; an Essay on Phenomenological Externalism. London: Routledge, 2003.

McDOWELL, J. Criteria, defeasibility, and knowledge. Proceedings of the British Academy, 1982.

Mind and World. Cambridge: Harvard UP, 1994.

McGINN, C. The concept of knowledge. Midwest Studies in Philosophy, IX, 1984.

NAGEL, Th. Davidson's new Cogito. In: HAHN, L. E. (Ed.). The Philosophy of Donald Davidson. Illinois: Open Court, 2000.

PUTNAM, H. The meaning of "meaning". Minnesota Studies in the Philosophy of Science, VII, 1975.

RORTY, R. Incorrigibility as the mark of the mental. Journal of Philosophy, 67, p. 399-424, 1970. 
STROUD, B. Understanding Human Knowledge in General. In: CLAY, M.; LEHRER, K. (Ed.). Knowledge and Skepticism. Boulder: Westview Press, 1989.

WILLIAMS, M. Unnatural Doubts. Princeton: Princeton UP, 1996.

WILLIAMSON, T. Knowledge and Its Limits. Oxford: Oxford UP, 2000.

WITTGENSTEIN, L. Philosophical Investigations. Oxford: Blackwell, 1953. 